\title{
A novel large regulator RNA, B2, partially overlaps the HEF1/NEDD9/Cas-L gene
}

\author{
MARINE MALLETER $^{1^{*}}$, CATHERINE JACQUOT ${ }^{1 *}$, DIMITRI MOREAU ${ }^{1}$, CHRISTOPHE TOMASONI $^{1}$, \\ MARIANNA TSVETANOVA ${ }^{1}$, IOANNA CHINOU ${ }^{2}$, MARCEL JUGE ${ }^{1}$, ALAIN PINEAU ${ }^{1}$, \\ PATRICE LE PAPE ${ }^{1}$ and CHRISTOS ROUSSAKIS ${ }^{1}$ \\ ${ }^{1}$ Université de Nantes, Nantes Atlantique Université, IICIMED/ERATU, Cancer du Poumon et Cibles Moléculaires, \\ UFR des Sciences Pharmaceutiques, 1 rue Gaston Veil, Nantes, F.44 035 Cedex 1, France; ${ }^{2}$ Division of \\ Pharmacognosy and Chemistry of Natural Products, University of Athens, \\ Panepistimiopolis Zografou, Athens 15771, Greece
}

Received September 21, 2009; Accepted December 23, 2009

DOI: 10.3892/ijmm_00000420

\begin{abstract}
The non-coding RNAs are new players in cellular and molecular biology. Indeed, quantitative and functional non-coding RNA has long been underestimated. There is a great diversity and it seems that much of the genome is transcribed into RNA, while only $1.2 \%$ of DNA information is translated into proteins. Non-coding RNA has been categorized according to different specifications so large non-coding RNA includes RNA with 300 to more than $10,000 \mathrm{bp}$. In this study, we propose a new non-coding RNA named $B 2$ discovered by differential display. $B 2$ is a nuclear RNA which is $51,011 \mathrm{bp}$ long with no significant open reading frame. This RNA has a continuous homology with the genomic DNA of the HEF1/ $N E D D 9 / C a s-L$ gene located on 6p24-p25. This homology has enabled us to characterize its structure by choosing overlapping fragments to perform several RT-PCRs. B2 RNA extends from $10 \mathrm{~kb}$ upstream of exon 1 of the $H E F 1$ gene on the $5^{\prime}$ end to exon $4 H E F 1$ on the $3^{\prime}$ end. In addition, a strategic choice of PCR primers enabled us to determine the location of $B 2$ in the subcellular compartment and then realtime PCR revealed overexpression of $B 2$ and $H E F 1$ in certain tissues such as thymus, cervix, liver, and spleen (among the 20 tissues analysed). B2 seems especially interesting in that it can regulate apoptosis and cell proliferation by modulating $H E F 1$. In addition, the fact that cytostatic treatments can induce $B 2$ reinforces the interest in this new potential target
\end{abstract}

Correspondence to: Dr Christos Roussakis, Université de Nantes, Nantes Atlantique Université, IICIMED/ERATU, Cancer du Poumon et Cibles Moléculaires, UFR des Sciences Pharmaceutiques, 1 rue Gaston Veil, Nantes, F.44 035 cedex 1, France

E-mail: christos.roussakis@univ-nantes.fr

"Contributed eaqually

Key words: large non-coding RNA, regulator RNA, HEF1, B2, A190, miRNA, cytostatic molecules in the development of anticancer treatments. These results show that this novel non-coding RNA is an attractive target.

\section{Introduction}

The non-small-cell lung carcinomas (NSCLC) represent $80 \%$ (1) of all cases of lung cancer but remain very resistant to all therapies currently in use such as chemotherapy, radiotherapy and surgery (2). These therapies focus on fast proliferating cells but such lung cancers have a slow doubling time, sometimes extending for many months, which explains their chemoresistance. In this context, a new approach would be to develop an appropriate strategy with a greater specificity for cancer cells and a lower toxicity for normal cells thus halting the slowly developing tumour. With this objective, we investigated the screening of original natural or synthetic chemical compounds to find new molecules with innovative mechanisms of action. Cytostatic substances, that induce the arrest of NSCLC cells in the G1-phase of the cycle and then cell death through the apoptosis pathway, should be considered as potential candidates. These selected compounds must also show low toxicity and marked antitumour activity confirmed by good results in vivo on nude mice xenografts. Two synthetic molecules, VT1 and A190, have been shown to exhibit all these activities and have already been patented by our laboratory. We have shown in our earlier studies on the NSCLC-N6 cell line that these substances trigger the overexpression of many genes involved in the arrest of G1 proliferation (3). Using the differential display technique and the NSCLC cell line (NSCLC-N6), a large RNA, named B2, was identified and located on the human chromosome 6 at the p24-p25 locus. B2 has no significant ORF (http://www. ncbi.nlm.nih.gov/gorf/gorf.html) and one very interesting feature is that it overlaps the HEF1 gene (4). HEFl belongs to a family of docking adapter proteins, including p130 Cas and Efs, named the Cas family $(5,6)$. The gene $H E F 1$ was discovered in 1996 but, in recent years, an increasing number of studies concerning this gene have been published. HEFl is involved in many different cellular functions, including migration, mitosis, differentiation and apoptosis $(7,8)$. 
HEF1 is a ubiquitous gene, present in many healthy tissues as well as in cell lines at different levels of expression. It is particularly expressed in lung tissue and pulmonary cell lines $(5,6,9)$.

The transcription of HEFl is lower in phase G1 and increases in phase $S$ reaching a maximum during phase $\mathrm{G} 2 / \mathrm{M}$. During the cell cycle, the $\mathrm{p} 105^{\mathrm{HEF} 1}$ protein and $\mathrm{p} 115^{\mathrm{HEF} 1}$, its phosphorylated form, present in phase G1, are cleaved by caspases into $\mathrm{p} 55^{\mathrm{HEF} 1}$ and $\mathrm{p} 65^{\mathrm{HEF} 1}$ in the $\mathrm{G} 2 / \mathrm{M}$ phase (6).

Moreover, HEF1 is concentrated in the centrosome and stimulates RhoA and Aurora A, two enzymes whose activation/inactivation is essential in the whole mitosis process (10). Dadke and colleagues (19) have shown that HEF1 is essential, in a very precise quantity, for the cell cycle to progress. The protein depletion resulting from RNA interference, as well as its overabundance, trigger apoptosis. Lastly, during mitosis, $\mathrm{p} 55^{\mathrm{HEF} 1}$ associates with the mitotic spindle and decreases suddenly at the end of mitosis as a result of proteosomal degradation.

The major role of $H E F 1$ in the apoptosis process was first revealed by Law and colleagues (5). They induced HEF 1 over-expression and showed that the cell cycle was blocked in the G1 phase. At the same time, they detected a new form of HEF 1 protein, the $\mathrm{p} 28^{\mathrm{HEF} 1}$. This protein is derived from the split of the protein $\mathrm{p} 65^{\mathrm{HEF} 1}$ by caspases 3 and/or 7 . It leads to cell death by destabilizing the focal adhesion site and stimulating anoikis. To date, the pro-apoptotic activity of $H E F 1$ has been fully demonstrated and closely linked with the presence of this $\mathrm{p} 28^{\mathrm{HEF} 1}$ protein in the cell during $H E F 1$ overexpression (11).

In the present study, we show that the RNA $B 2$, initially isolated through differential display, has a size of at least 51,011 bp and partially overlaps the $H E F 1$ gene. Furthermore, $10 \mathrm{~kb}$ of its sequences are located upstream of exon 1 of HEF1. We also report that $B 2$ has all the structural characteristics of a regulator 'large ncRNA'.

\section{Materials and methods}

Cell lines and cultures. Two cell lines were used in this study, A549 and NSCLC-N6 (L16), originating from an adenocarcinoma and an epidermoid lung cancer, respectively. The NSCLC-N6 (L16) is a cell line derived from a human nonsmall cell lung carcinoma of a previously untreated patient (moderately differentiated classified as T2NOM0) (12). The A549 line was obtained from ATCC (reference CCL-185) (13) and is known to have a wild-type p53 gene while NSCLC-N6 has a mutant p53 gene, so it is very close to tumours in situ.

These cell lines were cultured in Roswell Park Memorial Institute (RPMI)-1640 enriched with 100 IU of penicillin and $100 \mu \mathrm{g} / \mathrm{ml}$ of streptomycin, $2 \mathrm{mM}$ of glutamine and $5 \%$ foetal bovine serum. Cell culture plates were maintained in humidified incubators at $37^{\circ} \mathrm{C}$ in a $5 \% \mathrm{CO}_{2}$ atmosphere. $\mathrm{L} 16$ has a cell doubling time of $48 \mathrm{~h}$ in vitro, and A549 has a $24 \mathrm{~h}$ doubling time.

Extraction of total, nuclear and cytoplasmic RNA. Total RNA was extracted from NSCLC-N6 and/or A549 cell lines using Trizol ${ }^{\circledR}$ Reagent (Invitrogen, CA, USA) and chloroform according to the supplier's recommendations. Cell extracts were centrifuged at $12,000 \mathrm{x}$ g for $15 \mathrm{~min}$ at $4^{\circ} \mathrm{C}$. The aqueous phase containing RNA was transferred to a fresh tube. An equal volume of $70 \%$ ethanol was added to the aqueous phase and mixed by vortexing. Then, samples were transferred to an RNA spin cartridge supplied with the Trizol ${ }^{\circledR}$ plus RNA Purification Kit (PureLink ${ }^{\mathrm{TM}}$ Micro-to-Midi ${ }^{\mathrm{TM}}$ Total RNA Purification System, Invitrogen, Applied Biosystems) in order to remove DNA contamination. Then RNAs were eluted with RNase-free water.

The quality and concentration of purified RNAs were assessed using UV absorbance at 260/280 $\mathrm{nm}$ and samples were run on $1 \%$ agarose gel in order to check their quality. RNAs were stored at $-80^{\circ} \mathrm{C}$.

To separate nuclear and cytoplasmic RNAs, some steps were added before the same extraction was carried out. Cells were washed with cold PBS and removed without trypsin and centrifuged for $5 \mathrm{~min}$ at $1,000 \mathrm{~g}$. They were resuspended with a lysis buffer (Tris-Cl $50 \mathrm{mM}$ pH 8.0, $\mathrm{NaCl} 100 \mathrm{mM}$, $\mathrm{MgCl}_{2} 5 \mathrm{mM}$ and $0.5 \%$ nonidet P-40) and incubated for a few minutes on ice. Extracts were centrifuged for another $5 \mathrm{~min}$ at $13,000 \mathrm{~g}$. Supernatant was collected and pellets were washed twice with PBS. SDS $20 \%$ was added to each fraction (supernatant and pellet) and mixed thoroughly by shaking or vortexing. Proteinase $\mathrm{K}(20 \mathrm{mg} / \mathrm{ml})$ was added and the mix was incubated for $15 \mathrm{~min}$ at $37^{\circ} \mathrm{C}$.

DNase treatment. To remove genomic DNA prior to reverse transcription PCR, Turbo ${ }^{\mathrm{TM}}$ DNase (Ambion) was used. If the RNA concentration was $>200 \mu \mathrm{g} / \mathrm{ml}$, samples were diluted to $10 \mu \mathrm{g}$ nucleic acid/50 $\mu 1$. The $10 \mathrm{X}$ turbo DNase buffer was added to sample to a $1 \mathrm{X}$ final concentration. Next, $2 \mathrm{U}$ of turbo DNase was added to $10 \mu \mathrm{g}$ RNA in a $50 \mu 1$ reaction. Samples were incubated at $37^{\circ} \mathrm{C}$ for $30 \mathrm{~min}$. Then DNase Inactivation Reagent was added, the mix was incubated for 2 min then centrifuged at $10,000 \mathrm{x}$ g for $1.5 \mathrm{~min}$. The supernatant, which contained RNA, was transferred to fresh tubes.

$R T$-PCR. RT was carried out with $1 \mu \mathrm{g}$ of RNA in $10 \mu \mathrm{l}$ with $0.125 \mu \mathrm{g} / \mu 1$ random primers and RNase-free water. This mixture was denatured at $65^{\circ} \mathrm{C}$ for $10 \mathrm{~min}$ then kept on ice. Subsequently, it was completed to a final volume of $25 \mu 1$ with a mix containing $8 \mathrm{mM}$ of dNTP mix, $1 \mathrm{X}$ of M-MLV $5 \mathrm{X}$ reaction buffer, 25 units of recombinant RNasin ribonuclease inhibitor (Promega), and 200 units of M-MLV RT (Promega) and completed with RNase-free water. In order to check whether samples were contaminated by genomic DNA, the same mix was made with RNA without the reverse transcriptase. Following this step, samples were incubated for $2 \mathrm{~h}$ at $37^{\circ} \mathrm{C}$. cDNAs were stored at $-20^{\circ} \mathrm{C}$. After reverse transcription, cDNAs were used as a template for specific PCR.

$B 2$ was discovered as a 185 -bp fragment during RT differential display analysis in NSCLC-N6 cells $(4,14)$. In order to characterize the $5^{\prime}$ and 3 ' ends, RACE-PCR was first applied. Then DNA homology with the human chromosome 6 (GenBank No. AL 136139.6 and AL 139807.6 sequences) was exploited to perform RT-PCR. Primers were chosen so that two contiguous amplicons overlapped by at least $100-150 \mathrm{bp}$ (Fig. 1). All primers were designed using the Primer3 software (http://frodo.wi.mit.edu/cgibin/primer3/primer3_www.cgi). 


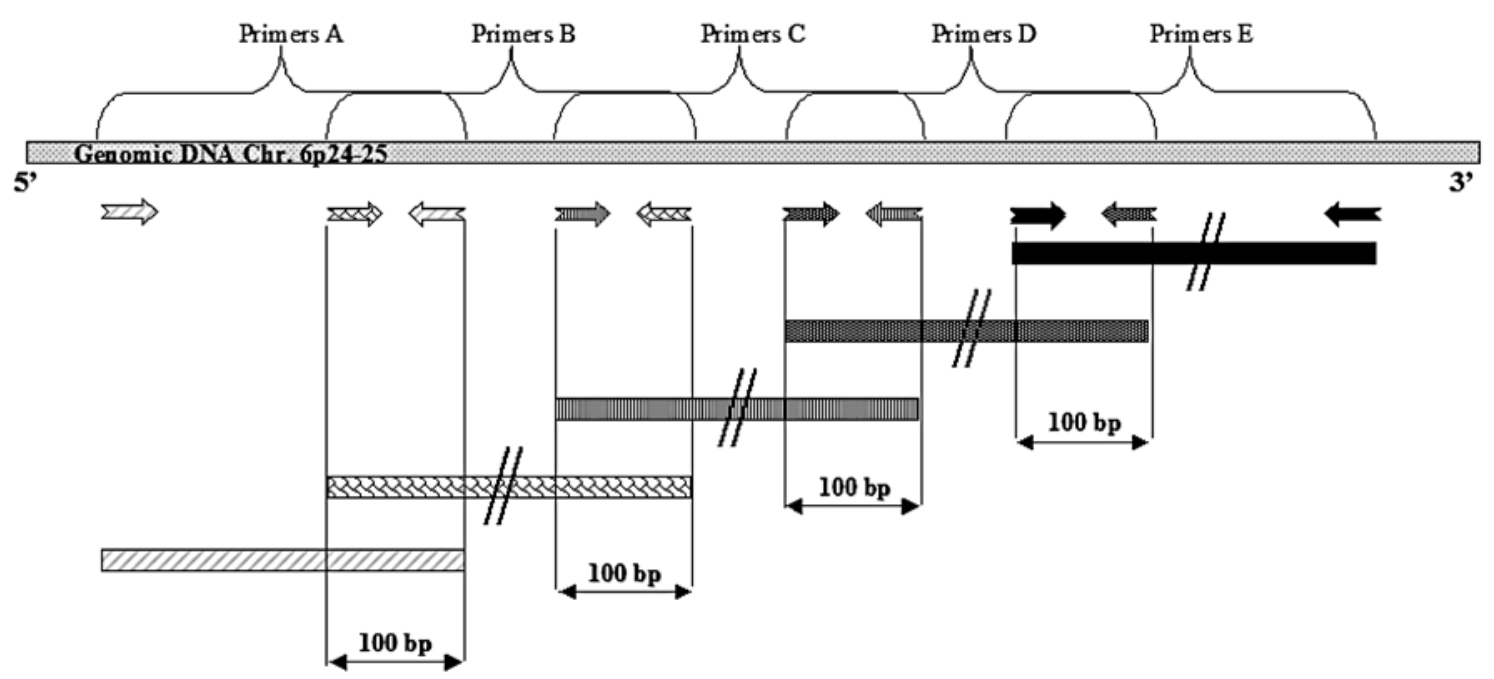

Figure 1. Schematic strategy for the identification of the $B 2$ sequence. The genomic DNA sequence of chromosome 6 was used for sequence primers designed with the website Primer 3. Each amplified fragment was $1 \mathrm{~kb}$ long and overlapped the upstream and downstream amplified fragment over about 100 bp.

Table I. Characteristics of the probes used.

\begin{tabular}{|c|c|c|c|}
\hline Probe name & Probe sequence & $\operatorname{Tm}^{\mathrm{a}}\left({ }^{\circ} \mathrm{C}\right)$ & Product size (bp) \\
\hline Left primer B2-EX1-04 & 5'-AGGCCGCAAGACTCATCTTA-3' & 60.5 & 533 \\
\hline Right primer B2-EX1-04 & 5'-GGATGCACTCCAACCAGACT-3' & 59.9 & \\
\hline Left primer B2-Si3 & 5'-CAACTTGGGGTGCATTCTTC-3' & 60.5 & 1,081 \\
\hline Right primer B2-Si3 & 5'-CTGAGAACCAGCATGATGACA-3' & 59.9 & \\
\hline Left primer $32-\mathrm{M}$ EX & 5'-CCGATATTCCTCAGGTACTCCA-3' & 60.0 & 931 \\
\hline Right primer $32-\mathrm{M}$ EX & 5'-ACATGTCTCGATCTATGAAAAAGA-3' & 60.0 & \\
\hline Left primer $32-\mathrm{M}$ INT & 5'-AGGCTATCCAGCGTACTCCA-3' & 60.0 & 320 \\
\hline Right primer B2-M INT & 5'-CCTCCATGATGCTGCTTACA-3' & 60.0 & \\
\hline Left primer HEF1 Exon 5 & 5'-AGCAGGGCTTAGGGAAAAAG-3' & 60.0 & 1,218 \\
\hline Right primer HEF1 Exon 5 & 5'-GCCAAGATATTCAGGGACCA-3' & 60.0 & \\
\hline
\end{tabular}

aTm, temperature

Among all the $B 2$ primers, B2-Si3 (Table I) matched the genomic sequence located between exons 2 and 3 of the $H E F 1$ gene and B2-Ex1-4 matched 4,000 bp upstream of the HEF1 exon 1 . Both were used to assess tissue expression and subcellular location.

HEF1 Exon5 primers (Table I) were used to assess HEF 1 expression on the Firstchoice Panel ${ }^{\circledR}, B 2-\mathrm{M}$-INT and $\beta 2-\mathrm{M}$-EX were used as controls for B2-microglobulin amplification. These primer pairs were as follows, left B2-M-INT matched on the junction of the genomic sequence before exon 2 and exon 2 of the gene were included, and right B2-M-INT on the junction of the genomic sequence before exon 3 and exon 3 were included. They were employed for specific nuclear amplification of B2-microglobulin RNA.

Left $B 2-\mathrm{M}-\mathrm{EX}$ matched on the junction exon 1-exon 2 and right $\mathrm{B2}-\mathrm{M}-\mathrm{EX}$ on the junction exon 3-exon 4 . They were used for cytoplasmic and nuclear amplification of 32 microglobulin RNA.

The PCR mix, consisting of $1 \mathrm{X}$ final of CoralLoad PCR buffer (Quiagen), $200 \mu \mathrm{M}$ of each dNTP, $0.5 \mu \mathrm{M}$ of right Primer, $0.5 \mu \mathrm{M}$ of left Primer and 2.5 units/reaction of Taq
DNA polymerase (Quiagen) was in a final volume of $25 \mu 1$. The amplifications were performed with the following protocol, $3 \mathrm{~min}$ at $94^{\circ} \mathrm{C}$ for initial denaturation then 39 cycles of amplification $\left(60 \mathrm{sec}\right.$ at $94^{\circ} \mathrm{C}, 60 \mathrm{sec}$ at $60^{\circ} \mathrm{C}$ for primer annealing, $60 \mathrm{sec}$ at $72^{\circ} \mathrm{C}$ for elongation), and $7 \mathrm{~min}$ at $72^{\circ} \mathrm{C}$ for final elongation. PCR products were analysed on $1 \%$ agarose gels stained with ethidium bromide (BET).

Race-PCR. The first step of this experiment consisted of a specific reverse transcription. It was achieved from tRNA extracted from A549 and L16. RNA $(1 \mu \mathrm{g})$ was used with $1 \mu \mathrm{M}$ of a specific primer (sequence) in $8.5 \mu 1$ final volume. The mix was denatured for $10 \mathrm{~min}$ at $65^{\circ} \mathrm{C}$ in a thermocycler. Then, the $5 \mathrm{X}$ reaction buffer (Promega), dNTPs $(10 \mathrm{mM})$, 20 IU RNase inhibitor (Promega), $100 \mathrm{mM}$ DDT, $200 \mathrm{IU}$ MMLV RT in $20 \mu 1$ final volume were added and incubated at $37^{\circ} \mathrm{C}$ for $50 \mathrm{~min}$, then $5 \mathrm{~min}$ at $70^{\circ} \mathrm{C}$. In the second step, a poly $\mathrm{C}$ was added to the $3^{\prime}$ end. The reaction buffer $5 \mathrm{X}$, dCTP $2 \mathrm{mM}$ and $10 \mathrm{U} / \mu 1$ were added to the previous mix and incubated for $15 \mathrm{~min}$ at $37^{\circ} \mathrm{C}$ and then at $70^{\circ} \mathrm{C}$ for $10 \mathrm{~min}$. The third step is named anchored PCR. It is a normal PCR 


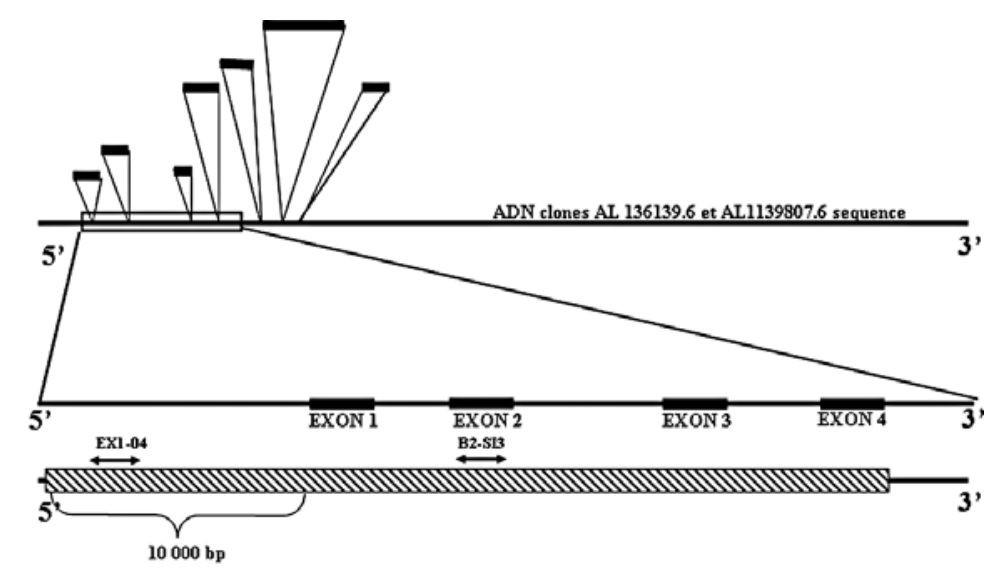

Figure 2. Schematic representation of homology between $H E F 1$ and $B 2$ in the region $6 \mathrm{p} 24-25 . B 2$ is a large ncRNA that originates $10 \mathrm{~kb}$ upstream of the first exon of $H E F 1$ and ends at the intronic region encompassing exon 4 of $H E F 1$. Specific primers of $B 2$ are shown in the figure. B2-SI3 spans the genomic sequence located between exons 2 and 3 of HEF1 and EX1-04 is located upstream of exon 1 of HEF1.

but there is only one primer (sequence) and oligo dG $10 \mu \mathrm{M}$ is different from a classic PCR.

RNA panel. The RNA panel was used first in RT-PCR and then in qRT-PCR. RT-PCR was performed to study the expression of the $B 2$ RNA in different tissues. The First Choice ${ }^{\circledR}$ Human Total RNA Survey Panel (Ambion) was used as a source of RNA from 20 different normal tissues (ovary, skeletal muscle, trachea, prostate, placenta, thymus, small intestine, bladder, testes, brain, colon, esophagus, kidney, spleen, adipose, liver, heart, thyroid, cervix, lung). B2-EX-1, B2-SI3, HEF1, and $\beta 2$-microglobulin (B2-M EX and INT) amplifications were each carried out with all 20 RNAs.

Then these 20 normal tissues were tested in real-time PCR. $B 2$ and HEF1 amplifications were carried out following the instructions of the manufacturer of SYBR Green PCR mix (Applied Biosystems) on the ABI Prism ${ }^{\circledR}$ Sequence Detection System 7300. The primers were designed using Primer 3 (as described above). For the gene HEF 1 , the primers were chosen on two different exons ( 1 and 2 ) to be sure of no interference between the amplifications of $H E F 1$ and $B 2$. The primer sequences were HEF1, forward 5'-CGCT GCCGAAATGAATAT-3', reverse 5'-CCCTGTGTTCTGCT CTATGACG-3'; $B 2$, forward 5'-ATTCCCTTGGATCTTGC CTT-3', reverse 5'-CGTGAGGTCTGCCACTAC-3'. The relative expression was normalized with $\beta$-actin added to each gene, forward 5'-ATTCCCTTGCCTTCTTGGAT-3', reverse 5'-CGTGAGGTCTGCCACTACAG-3'. A control sample was used for each PCR to check the genomic DNA contamination of the cDNA template. The results were analysed using GenAmp 7300 SDS (Applied Biosystems).

\section{Results}

$B 2 \mathrm{RNA}$ is at least $50 \mathrm{~kb}$. From the $185 \mathrm{bp}$ long initial fragment, we carried out as many as 117 RT-PCR (sequences not shown) to characterize the whole sequence of the B2 RNA. Each amplicon was a 1-kb fragment and overlapped the previous and the next over at least 100 to 150 bp (Fig. 1).
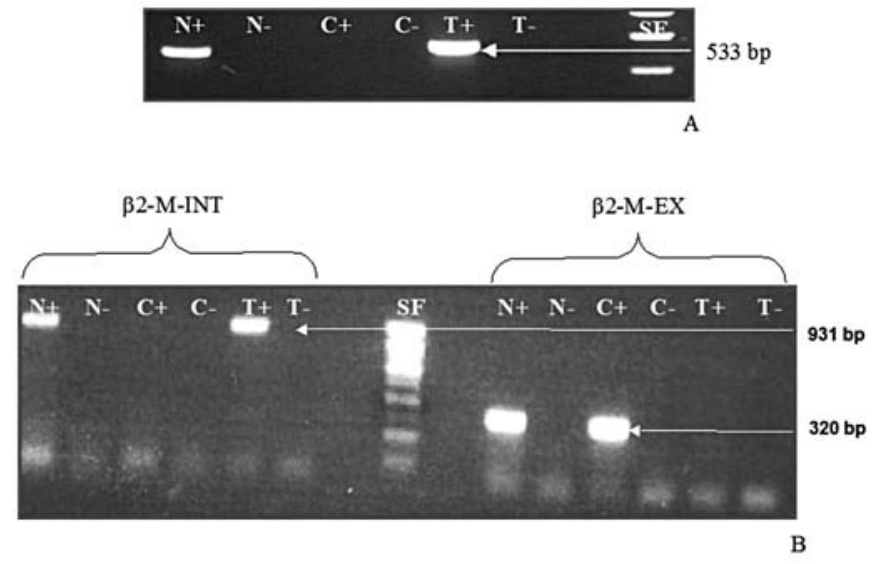

Figure 3. PCR amplification analysed on agarose gel $1 \%$ stained by BET. Cytoplasmic RNA and nuclear RNA were analysed by RT-PCR with B2EX1-04 primers (A) and control primer (B2-M-INT and B2-M-EX) (B). (A) nuclear fraction with $\left(\mathrm{N}^{+}\right)$or without $\left(\mathrm{N}^{-}\right)$reverse transcription; cytoplasmic fraction with $\left(\mathrm{C}^{+}\right)$or without $\left(\mathrm{C}^{-}\right)$reverse transcription; $\mathrm{T}^{+}$genomic DNA, $\mathrm{T}^{-}$ negative control; SF. (B) nuclear fraction with $\left(\mathrm{N}^{+}\right)$or without $\left(\mathrm{N}^{-}\right)$reverse transcription; cytoplasmic fraction with $\left(\mathrm{C}^{+}\right)$or without $\left(\mathrm{C}^{-}\right)$reverse transcription; $\mathrm{T}^{+}$genomic DNA, $\mathrm{T}^{-}$negative control. First six lanes show the amplification with B2-M-INT and the last six lanes with B2-M-EX.

To date, considering all the fragments joined together, $B 2$ spreads over at least $51,011 \mathrm{bp}$. It shows a total homology with the region 6p24-p25 of the human genome without any interruption. So it is formed with a single large exon.

$B 2$ overlaps one part of the HEF 1 gene, $10 \mathrm{~kb}$ match upstream of the exon $1 H E F 1$ and the last 40,000 bp spread from exon 1 to exon 4 of $H E F 1$ (Fig. 2). No significant ORF was identified in the whole sequence. Finally, the $5^{\prime}$ end is defined. The sequence was published in Genbank, GQ497714.

B2 is a nuclear RNA. RT-PCR was performed on both nuclear and cytoplasmic RNAs. B2-Si3 as well as B2-EX-1 primers show amplification only on the nuclear RNA extract (Fig. 3). B2-Si3 lies on the initial differential display located in the 
○

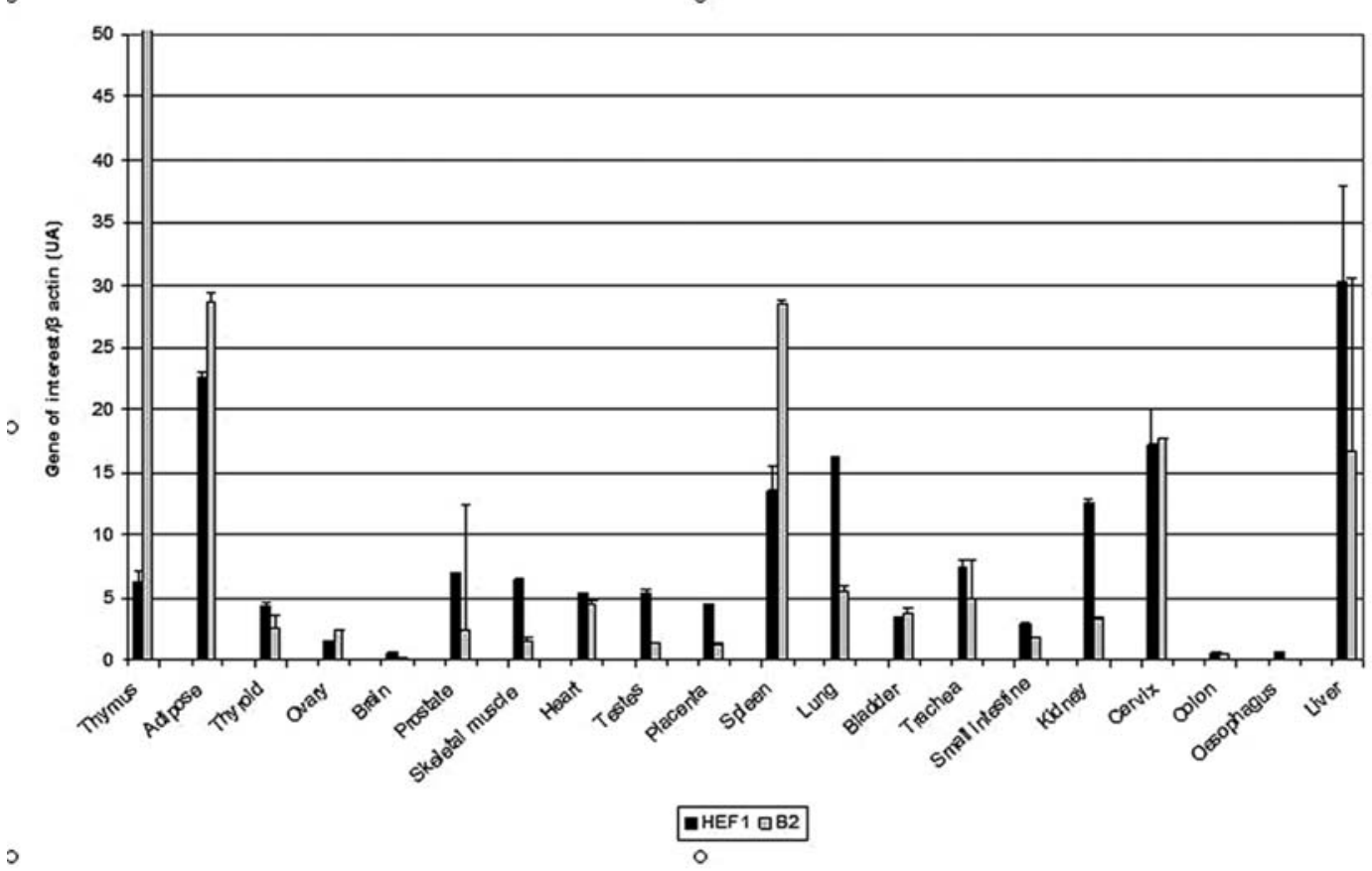

Figure 4. Expression of the gene B2 (grey) and HEF1 (black) on FirstChoice ${ }^{\circledR}$ Human Total RNA Survey Panel (Ambion) by real-time PCR.

genomic sequence between exons 2 and 3 of the $H E F 1$ gene but B2-EX4-1 matches the part upstream of exon 1 of $H E F 1$, thus ruling out any interference with $H E F 1$ mRNA. We have shown only the result with B2-EX4-1 because it is the same result.

Then RT-PCR was carried out with B2-M-EX and B2-MINT primers on the same RNA extracts and the same cDNA. As might be expected, PCR amplification with B2-M-INT was possible only on the nuclear RNA extract. This experiment, with the DNase treatment, confirms that nuclear RNA could actually be amplified in our extracts. Moreover, it also confirms that no nuclear contaminants were present in the cytoplasmic RNA fraction. With B2-M-EX, PCR fragments were present both in the cytoplasmic and in the nuclear fraction because of the mRNA maturation that occurred in the nuclear compartment. Moreover, these latter primers enabled us to validate the RT step.

B2 RNA is as ubiquitous as the HEF1 gene. As B2 overlaps the $H E F 1$ gene, we were interested in the relation between these two genes. More precisely, we investigated whether $B 2$ and $H E F 1$ were expressed in the same tissues. To test this, we chose to use the same commercial RNA panel that had been employed in a recent study on HEF1 (9). So additional RTPCR was performed with B2-Si3 and B2-EX1-4 primers. Each primer pair was tested on all 20 RNA extracts.

The expression of $B 2$ RNA could be amplified in all normal tissues tested, such as for $H E F 1$. The expression of these two genes were analysed with real-time PCR.

Quantification of B2 RNA and the HEF1 gene. As these 2 genes could be amplified in the 20 tissues tested, we investigated this directly using quantitative RT-PCR to analyse $B 2$ and $H E F 1$ expression in mRNAs prepared from 20 human tissues (Fig. 4). HEF 1 was most abundant in adipose, lung, cervix, liver and
Table II. B2 and HEF1 amplification from different tissues of the FirstChoice ${ }^{\circledR}$ Human Total RNA Survey Panel.

\begin{tabular}{lccl}
\hline $\begin{array}{l}\text { Tissue } \\
(+)\end{array}$ & $\begin{array}{c}\text { Expression } \\
B 2\end{array}$ & $\begin{array}{c}\text { Expression } \\
\text { HEF } 1\end{array}$ & \multicolumn{1}{c}{$\begin{array}{c}\text { Tissue } \\
(\mathrm{x})\end{array}$} \\
\hline Bladder & $+\mathrm{x}$ & $+\mathrm{x}$ & Skeletal muscle \\
Testes & $+\mathrm{x}$ & $+\mathrm{x}$ & Heart \\
Oesophagus & $+\mathrm{x}$ & $+\mathrm{x}$ & Cervix \\
Brain & $+\mathrm{x}$ & $+\mathrm{x}$ & Lung \\
Trachea & $+\mathrm{x}$ & $+\mathrm{x}$ & Spleen \\
Colon & $+\mathrm{x}$ & $+\mathrm{x}$ & Kidney \\
Placenta & $+\mathrm{x}$ & $+\mathrm{x}$ & Small intestine \\
Thymus & $+\mathrm{x}$ & $+\mathrm{x}$ & Liver \\
Thyroid & $+\mathrm{x}$ & $+\mathrm{x}$ & Adipose \\
Ovary & $+\mathrm{x}$ & $+\mathrm{x}$ & Prostate \\
\hline
\end{tabular}

spleen and was detected at lower levels in the other tissues while $B 2$ was most abundant in thymus, adipose, cervix, liver and spleen and was detected at lower levels in the other tissues (Table II). These results are consistent with the study of Golemis et al (9).

\section{Discussion}

Since the sequencing of the entire genome, we know that the transcriptome is much bigger than had previously been supposed. Particularly, in recent years numerous studies have shown the importance of small non-coding RNAs such as miRNA, small nuclear and nucleolar RNAs, in the regulation of gene expression. However, a new class of non-coding RNAs has also now emerged which comprises RNAs of several thousand bp. Most of these 'large RNAs' are not spliced and 
are at least $10 \mathrm{~kb}$ in size. Their function is not yet clear but some are involved in the regulation of the expression of adjacent genes. Among the best known is Air, a non-coding unspliced RNA of $108 \mathrm{~kb}$ which acts as the 'silencer' for three genes coding for proteins of the igf2r cluster (15). Another is NTT, an RNA of $17 \mathrm{~kb}$ situated in 6q23-q24 next to the receptor $\gamma$ of interferon, whose expression it regulates in $\mathrm{CD} 4^{+}$cells. Finally, there is Xist, a nuclear RNA of $17 \mathrm{~kb}$ which is involved in the transcriptional silencing of one of the two X chromosomes in the female embryo (16).

The present study revealed a new large non-coding RNA, called $B 2$, which is $51 \mathrm{~kb}$ long. It is nuclear, has no open reading frame and is found in the p24-p25 region of chromosome 6. It is particularly interesting because it presents a total and continuous homology with genomic DNA, and thus consists of one large exon that overlaps the HEF1 gene from exon 4 to $>10,000 \mathrm{bp}$ upstream of exon 1 . In addition, we have compared the tissue expression of $B 2$ and HEF1 in 20 RNAs of healthy tissues. Our results show that these two molecular targets are expressed in all the healthy tissues of the panel. However, HEF1 is overexpressed in adipose, spleen, cervix, liver, and lung. Moreover, when the expression of $B 2$ is weaker, as in liver, there is an overexpression of HEF1. These results are in agreement with those published by Golemis and co-workers who showed an overexpression of HEF1 in lung (9). $B 2$, however, is overexpressed in adipose, spleen, cervix, liver and thymus (Fig. 4). In fact, in the thymus, $B 2$ is greatly overexpressed compared to $H E F 1$. Collectively, the results show that overexpression of $B 2$ leads to the repression of the $H E F 1$ gene, as observed in the thymus, adipose, and spleen. Conversely, when $B 2$ is weakly expressed, HEF1 is overexpressed as seen in the lung and kidney. These results confirm a link between the overexpression of $B 2$ and the repression of $H E F 1$, which implies that the non-coding RNA $B 2$ regulates the $H E F 1$ gene.

This could occur by numerous mechanisms, identified to varying degrees in previous studies. Among the best known is transcriptional interference. This results from a strong promoter acting on a weaker promoter located downstream and thus affects two genes close together (17). Another mechanism can explain this regulation of $H E F 1$ by $B 2$; due to its nuclear location and large size, $B 2$ can induce a loop in the chromatin enabling the repression of $H E F 1$. Such chromatin loops have already been suggested to explain how much ncRNA takes part in the phenomenon of higher-order chromatin silencing (17). Alternatively, the transcription of such a large RNA could simply enable all the transcription factors to be sequestered thus preventing gene HEFl transcription (17). Other hypotheses are also feasible; $B 2$ is a non-coding nuclear RNA which could form an RNA/DNA triple helix during the transcription of the RNA of HEF1 thus blocking it as has already been shown (17). The final hypothesis to be considered here is that $B 2$ acts as an RNA precursor of miRNA. In fact, according to one study, $H 19$ was one of the first non-coding RNAs to be identified and has recently been described as a precursor of miRNA (18). As B2 RNA overlaps several exons of the HEFl gene, it seems possible that $B 2$ could induce miRNA directed against $H E F 1$ mRNA. Moreover, bioinformatic analysis shows that the sequence of the $B 2$ gene can generate numerous sequences typical of miRNA. These sequences would be recognized and cleaved into pre-miRNA by Drosha in the nuclear compartment then transferred by exportin 5 into the cytoplasm where the Dicer complex would transform these pre-miRNA into miRNA (18).

The HEF 1 gene is known for its involvement in the control of cell growth, in apoptosis and in cell motility through its interaction with cellular adhesion sites and the mitotic spindle $(5,19)$. HEF1 is responsible for the production of 4 different proteins, $\mathrm{p} 115^{\mathrm{HEF1}}$ and $\mathrm{p} 105^{\mathrm{HEF1}}$ cleaved into $\mathrm{p} 65^{\mathrm{HEF} 1}$ and $\mathrm{p} 55^{\mathrm{HEF} 1}$ by caspases. Moreover, Law et al showed that overexpression of HEF1 in MCF-7 cells increased the proteolytic activity of caspase 3 and/or 7 leading to the cleavage of $\mathrm{p} 65^{\mathrm{HEF} 1}$ into p28 ${ }^{\mathrm{HEF1}}$ (20). The C-terminal region of this $\mathrm{p} 28^{\mathrm{HEF1}}$ seems to be responsible for the pro-apoptotic activity of $H E F 1$. In fact, p2 $8^{\text {HEF1 }}$ favours the cleavage of Focal Adhesion Kinase (FAK) leading to apoptosis (11).

Cell proliferation, motility and growth are the three target areas of anticancer chemotherapy. In this approach, our aim was to demonstrate that $H E F 1$ and $B 2$ are involved in halting proliferation by inducing apoptosis in the anticancer chemotherapy of lung cancer. The work of Moreau et al (20) has highlighted the antitumour effect of the cytostatic molecule A190 on nude mice xenografted by non-small cell lung carcinomas.

The results that we have obtained on the two lung cell lines A549 and L16 during treatment with A190 confirm the existence of $H E F 1$ gene regulation by $B 2$ RNA.

A190 induces cell apoptosis at the same time as it increases the expression of both $H E F 1$ and $B 2$ RNA. This overexpression occurs after $60 \mathrm{~h}$ of treatment and falls dramatically after $70 \mathrm{~h}$. If non-coding $B 2$ RNA acts as a precursor of miRNA, it would enable the production of miRNA directed against $H E F 1$ mRNA, explaining the sudden drop in the level of expression. The decrease in $H E F 1$ mRNA would lead to a lack of $H E F 1$ protein which would fall below the minimal threshold required for the cell cycle to progress and apoptosis would be triggered.

The team of Golemis $(7,8)$ has demonstrated that the normal progression of the cell cycle requires a precise quantity of the HEF1 protein. This must lie between an upper and a lower limit, thus three possible situations can occur. If there is the correct quantity of HEF1 protein in the cell, the truncated form $\mathrm{p} 55^{\mathrm{HEF} 1}$ contributes to the normal cell cycle and mitosis can take place. However, if there is excess HEF1, above the upper limit, then the $\mathrm{p} 65^{\mathrm{HEF} 1}$ form, also in excess, is cleaved into $\mathrm{p} 28^{\mathrm{HEF} 1}$ which initiates apoptosis. Similarly, if there is insufficient HEF1, below the lower limit, the cell cycle will be irreversibly stopped in the very early stages of mitosis.

The latter situation would be applicable during treatment of cells A549 and L16. This would explain how the molecule A190 could trigger apoptosis even in the absence of p28 $8^{\text {HEF } 1}$ which has never been detected by Western blotting (data not shown).

There remains a great deal to discover about large ncRNAs. Their study is at an early stage and it would not be surprising to see their importance grow in numerous diseases, particularly in cancer. Our identification here of such an RNA in lung cancer cells is one illustration. $B 2$ seems especially interesting in that it can regulate apoptosis and cell proliferation by 
modulating $H E F 1$. In addition, the fact that cytostatic treatments can induce $B 2$ reinforces the interest of this new potential target in the development of anticancer treatments.

\section{Acknowledgements}

We thank La Ligue Départementale Contre Le Cancer, Région Pays de La Loire and Professors P. Tsits and Antoniadou-Vyza and Anne-Laure Biang for their contributions.

\section{References}

1. Lilenbaum RC, Herndon JE 2nd, List MA, Desch C, Watson DM, Miller AA, Graziano SL, Perry MC, Saville W, Chahinian P, Weeks JC, Holland JC, et al: Single-agent versus combination chemotherapy in advanced non-small-cell lung cancer: the cancer and leukemia group B (study 9730). J Clin Oncol 23:190-196, 2005.

2. Ettinger DS: Overview and state of the art in the management of lung cancer. Oncology 18: 3-9, 2004.

3. Carbonnelle D, Jacquot C, Lanco X, Le Dez G, Tomasoni C, Briand G, Tsotinis A, Calogeropoulou T and Roussakis C: Upregulation of a novel mRNA (NY-CO-1) involved in the methyl 4-methoxy-3-(3-methyl-2-butenoyl) benzoate (VT1)-induced proliferation arrest of a non-small-cell lung carcinoma cell line (NSCLC-N6). Int J Cancer 92: 388-397, 2001

4. Jacquot C, Carbonnelle D, Tomasoni C, Papaconstadinou A, Roussis V and Roussakis C: Identification of a novel putative non-coding RNA involved in proliferation arrest of a non-small cell lung carcinoma cell line treated with an original chemical substance, methyl-4-methoxy-3-(3-methyl-2-butanoyl) benzoate. Int J Oncol 25: 519-527, 2004.

5. Law SF, Estojak J, Wang B, Mysliwiec T, Kruh G and Golemis EA: Human enhancer of filamentation 1, a novel p130cas-like docking protein, associates with focal adhesion kinase and induces pseudohyphal growth in Saccharomyces cerevisiae. Mol Cell Biol 16: 3327-3337, 1996.

6. Law SF, Zhang YZ, Klein-Szanto AJ and Golemis EA: Cell cycle-regulated processing of HEF1 to multiple protein forms differentially targeted to multiple subcellular compartments. Mol Cell Biol 18: 3540-3551, 1998.

7. Law SF, O'Neill GM, Fashena SJ, Einarson MB and Golemis EA: The docking protein HEF1 is an apoptotic mediator at focal adhesion sites. Mol Cell Biol 20: 5184-5195, 2000.
8. O'Neill GM, Seo S, Serebriiskii IG, Lessin SR and Golemis EA: A new central scaffold for metastasis: parsing HEF1/CasL/NEDD9. Cancer Res 67: 8975-8979, 2007.

9. Singh MK, Dadke D, Nicolas E, Serebriiskii IG, Apostolou S, Canutescu A, Egleston BL and Golemis EA: A novel cas family member, HEPL, regulates FAK and cell spreading. Mol Biol Cell 19: 1627-1636, 2008.

10. Pugacheva EN and Golemis EA: HEF1-aurora A interactions: points of dialog between the cell cycle and cell attachment signaling networks. Cell Cycle 5: 384-391, 2006.

11. O'Neill GM and Golemis EA: Proteolysis of the docking protein HEF1 and implications for focal adhesion dynamics. Mol Cell Biol 21: 5094-5108, 2001.

12. Roussakis C, Gratas C, Audouin AF, Le Boterff J, Dabouis C, Andre MJ, Moyon E, Vo NH, Pradal G and Verbist JF: Study of in vitro drug sensitivity on a newly established cell line from a primary bronchial epidermoid carcinoma of human origin (NSCLCN6). Anticancer Res 11: 2239-2244, 1991.

13. Giard DJ, Aaronson SA, Todaro GJ, Arnstein P, Kersey JH, Dosik $\mathrm{H}$ and Parks WP: In vitro cultivation of human tumors: establishment of cell lines derived from a series of solid tumors. J Natl Cancer Inst 51: 1417-1423, 1973.

14. Liang P and Pardee AB: Differential display of eukaryotic messenger RNA by means of the polymerase chain reaction. Science 257: 967-971, 1992.

15. Seidl CI, Stricker SH and Barlow DP: The imprinted Air ncRNA is an atypical RNAPII transcript that evades splicing and escapes nuclear export. EMBO J 25: 3565-3575, 2006.

16. Clerc P and Avner P: Role of the region 3 ' to Xist exon 6 in the counting process of X-chromosome inactivation. Nat Genet 19: 249-253, 1998.

17. Pauler FM, Koerner MV and Barlow DP: Silencing by imprinted noncoding RNAs: is transcription the answer? Trends Genet 23: 284-292, 2007.

18. Cai X and Cullen BR: The imprinted H19 noncoding RNA is a primary microRNA precursor. RNA 13: 313-316, 2007.

19. Dadke D, Jarnik M, Pugacheva EN, Singh MK and Golemis EA: Deregulation of HEF1 impairs M-phase progression by disrupting the RhoA activation cycle. Mol Biol Cell 17: 12041217, 2006.

20. Moreau D, Jacquot C, Tsita P, Chinou I, Tomasoni C, Juge M, Antoniadou-Vyza E, Martignat L, Pineau A and Roussakis C: Original triazine inductor of new specific molecular targets, with antitumor activity against non-small cell lung cancer. Int J Cancer 123: 2676-2683, 2008. 